\title{
COMPETITIVIDADE DA SOJA E A GERAÇÃO DE DIVISAS ${ }^{1}$
}

\author{
Maria Auxiliadora de Carvalho ${ }^{2}$ \\ César Roberto Leite da Silva \\ Arthur Antonio Ghilardi ${ }^{4}$
}

Resumo - A elevada dependência externa da economia brasileira torna a geração de divisas uma preocupação permanente. Ao longo da década de 1990, a soja liderou as exportações agrícolas e se tornou a principal fonte de divisas. Logo, analisar sua competitividade contribui para a compreensão da dinâmica econômica brasileira. Com o emprego de um conjunto de indicadores foi possível concluir que houve aumento de competitividade no comércio de grão de soja a partir de 1997, mas ocorreram perdas no comércio de farelo; que houve aumentos expressivos de produtividade da lavoura durante a década de 1990, mas, depois disso, o incremento da produção foi devido ao aumento de área; que entre 1991 e 2003 a participação dos fertilizantes, corretivos e defensivos no custo de produção dobrou, o valor das exportações de soja e derivados foi multiplicado por 4 e a despesa com insumos importados, multiplicada por 10; e que parte da competitividade alcançada não foi sustentável, dado que depende da conjuntura internacional e expõe o país a riscos decorrentes da grande concentração das fontes de divisas.

Palavras-chave: Competitividade, agricultura, soja, mercado externo.

\section{Introdução}

A dinâmica econômica brasileira é marcada pela dependência externa, $o$ que torna a geração de divisas pela exportação fundamental para minimizar a vulnerabilidade do país e propiciar seu crescimento sustentável. Como a abordagem da competitividade relacionada ao desempenho exportador

Recebido em 09/08/2005 Aceito em 09/09/2005

2 Pesquisadora do Instituto de Economia Agrícola. Rua 13 de Maio, 1610, ap. 51 - Bela Vista - CEP 01327-002 São Paulo - SP. (macarvalho@iea.sp.gov.br).

3 Pesquisador do Instituto de Economia Agrícola. Rua Teixeira da Silva, 426, ap. 31 - Paraíso - CEP 04002031 São Paulo-SP (crlsilva@iea.sp.gov.br).

4 Pesquisador do Instituto de Economia Agrícola. Av. Onze de Junho, 99, ap. 72, Bl. 2 - V. Clementino - CEP 04041-050 São Paulo-SP (arthurghi@iea.sp.gov.br). 
busca confrontar a posição do país diante dos concorrentes internacionais, ela pode ser empregada com proveito na análise da economia brasileira ${ }^{5}$.

A partir desse conceito de competitividade, poucos números podem indicar que a agricultura brasileira no agregado tem mostrado razoável sucesso: entre 1990 e 2003 a participação do país nas exportações agrícolas mundiais se elevou de 2,7 para 4,0\% (FAOSTAT, 2005). Além disso, o setor sustentou expressivos superávits comerciais, mesmo nas etapas de valorização da moeda local, o que fez aumentar a importância econômica da agricultura, que entre 1990 e 2003 acumulou crescimento do PIB de $57 \%$, enquanto o conjunto da economia brasileira cresceu apenas $34 \%$.

Para uma avaliação mais precisa da competitividade, Fajnzylber (1988) considerou que não basta avaliar o desempenho das exportações, até porque isso pode ser conseguido à custa de baixos salários, de manipulação da taxa de câmbio ou de subsídios à exportação, o que caracterizaria competitividade espúria. A competitividade autêntica só seria conseguida pelo progresso técnico, único meio de aumentar a participação do país no mercado internacional e com melhoria da qualidade de vida de sua população.

Também sob esse enfoque, a agricultura vem dando mostras de sucesso. Há pesquisas que avaliam a produtividade parcial dos fatores e, ou, a produtividade total, e todas indicam progresso técnico do setor, o que implica ganhos de competitividade. Gasques et al. (2004) constataram, no período de 1975-2002, que o índice do produto agrícola cresceu $160,66 \%$, enquanto o índice dos insumos aumentou apenas $21,12 \%$, revelando significativo incremento da produtividade total dos fatores (PTF): média de 3,3\% a.a. Sua análise por subperíodos revela que o aumento da PTF foi mais expressivo a partir da década de 1990: de $1,52 \%$ a.a. entre 1980 e 1989 evoluiu para $4,88 \%$ a.a. nos 10 anos seguintes e para 6,04\% a.a. de 2000 a 2002. Destaca-se que, no passado, cabia à terra a maior parcela dos ganhos de produtividade, mas de 1998 a 2002 a produtividade do trabalho cresceu mais que a da terra.

Resenha de Haguenauer (1989), que subdivide as análises da competitividade entre as que associam o desempenho na exportação (maior parte) à eficiência e as que consideram as condições gerais de produção. 
Dias e Amaral (2001) argumentaram que até na década de 1980 o setor agrícola contava com forte aparato de apoio público e que a perda desse apoio na década seguinte induziu os agricultores ao ajuste microeconômico das unidades produtivas para reduzir custos, resultando em ganhos expressivos de produtividade da terra, diminuição da área cultivada e forte queda do emprego de mão-de-obra ${ }^{6}$.

Brandão et al. (2005), considerando que a área plantada com as lavouras se manteve praticamente constante ao longo da década de 1990 e passou a crescer celeremente a partir de então, chegaram a relatar que houve mudança no padrão do crescimento agrícola brasileiro. Atribuíram grande parte dessa mudança à lavoura da soja, que vem ocupando espaços crescentes em termos de área e de importância econômica para o país.

A conclusão de que a soja vem liderando os ganhos de produtividade também pode ser inferida do trabalho de Vicente (2004), cuja análise limitada ao setor de lavouras para o período de 1975-1995 apontou que a maior elevação da PTF aconteceu na Região Centro-Oeste, destacandose pela máxima PTF o Estado de Mato Grosso (inclusive Mato Grosso do Sul), onde a soja ocupa cerca de $70 \%$ da área plantada ${ }^{7}$.

Como o Brasil vem se tornando a cada dia mais dependente do bom desempenho da agricultura e tendo em conta que a lavoura da soja sobrepuja as demais em termos de dinamismo econômico, este trabalho objetivou desenvolver uma análise de sua competitividade no mercado internacional a partir da década de 1990, com atenção especial ao seu papel de provedora de divisas. Aênfase nesse aspecto se justifica porque, embora a lavoura da soja ocupe a primeira colocação entre os produtos agrícolas exportados, é também a principal consumidora de fertilizantes e defensivos, insumos que vêm liderando o crescimento das despesas do setor com importação.

\footnotetext{
6 Na análise que abrange o período de 1986-1998, observaram desempenho superior dos produtos de consumo doméstico (milho, arroz e feijão) em relação aos exportáveis café e cacau, que tiveram redução de produtividade (Dias; Amaral, 2001).

7 Pelos dados da Companhia Nacional de Abastecimento (CONAB), na safra de 2004/05 a soja ocupou 70,8\% da área plantada no Mato Grosso e 66,7\% no Mato Grosso do Sul (<http://www.conab.gov.br〉. Acesso em: 28 Fev.05>).
} 
O presente trabalho é composto de três partes, além desta introdução. A primeira apresenta os indicadores e fontes de dados utilizados para avaliação da competitividade da soja brasileira, a segunda discute os resultados encontrados através do emprego desses indicadores, e a última parte destaca os aspectos mais relevantes da análise.

\section{Metodologia}

A partir da acepção de competitividade relacionada ao desempenho foram empregados indicadores de fácil compreensão, para avaliar a evolução do comércio brasileiro de soja depois de 1990. São eles:

Market-share

$s_{k i}=\frac{X_{k i}}{X_{k w}} \cdot 100$

em que $X=$ valor da exportação; $\mathrm{k}=$ soja; $\mathrm{i}=$ Brasil; e $w=$ mundo.

Indicador esse que aponta a participação percentual do país no mercado internacional de determinado produto.

Vantagem relativa na exportação

$$
v r e_{k i}=\ln \left[\frac{X_{k i} / X_{k r}}{X_{m i} / X_{m r}}\right]
$$

em que: $r=$ todos os países, exclusive $i$; $e m=$ todos os produtos, exclusive $k$. 
Indicador empregado por Vollrath (1989) para aferir a competitividade de um país em determinado produto, em comparação com os outros exportadores e outros produtos. Se vre ${ }_{k i}=0$ significa que a participação das exportações do produto $k$ no total das exportações do país $i$ é idêntica à observada, em média, nos demais países, caracterizando uma situação neutra, ou seja, o país não revela vantagem nem desvantagem no comércio do produto $k$. Se $v r e_{k \mathrm{i}}>0$, o país $i$ revela vantagem na exportação de $k$ e, naturalmente, se vre ${ }_{k i}<0$, desvantagem.

Participação de $k$ no total da exportação

Participação do saldo comercial de $k$ no PIB agrícola

$x_{k i}=\frac{X_{k i}}{X_{i}} \cdot 10 \frac{\left(X_{k i}-M_{k i}\right)}{y_{i}} \cdot 100$

em que : $y=$ PIB agrícola; e $M=$ valor da importação.

Indicador esse que aponta a importância relativa do saldo comercial de $k$ no PIB agrícola.

Participação do comércio de $k$ no comércio total dos produtos agrícolas

$$
q_{k i}=\frac{X_{k i}+M_{k i}}{X_{i}+M_{i}} \cdot 100
$$

Indicador esse utilizado por Gasques e Conceição (2002) que aponta o peso relativo do produto k no intercâmbio comercial agrícola do país. 
Participação dos insumos importados na exportação

$i_{k i}=\frac{M_{k j i}}{X_{k i}} \cdot 100$

em que: $j=$ fertilizantes, corretivos e defensivos.

Participação dos insumos no custo de produção

$c_{k i}=\frac{I_{k i}}{C_{k i}} \cdot 100$

em que: $I=$ valor gasto com fertilizantes, corretivos e defensivos; e $C=$ custo operacional da produção.

Os dados referentes ao comércio exterior procedem do banco de dados da Organização para Alimentação e Agricultura das Nações Unidas FAO e estão disponíveis em <http://faostat.fao.org/faostat/ collections?version=ext\&hasbulk=0 $>$. As informações do PIB agrícola foram obtidas no site < http://www.ipeadata.gov.br/>. A participação da soja no consumo de fertilizantes e defensivos procede, respectivamente, do Sindicato Nacional da Indústria de Produtos para Defesa Agrícola SINDAG e da Associação Nacional para Difusão de Adubos ANDA, e por vários anos foi compilada por Ferreira (1996) e Neves et al. (2002ab). Os dados de custo de produção no período de 1991-1994 são do Instituto de Economia Agrícola (IEA) e no restante da série, da publicação Agrianual (FNP Consultoria). Os índices de preços pagos por agrotóxicos e fertilizantes procedem do Ministério da Agricultura, Pecuária e Abastecimento e estão disponíveis em <http://www.agricultura.gov.br/>. 


\section{Resultados e discussão}

As dificuldades enfrentadas pela agricultura no início de 2005 levaram a uma reversão do otimismo que prevaleceu por anos e ao retorno das preocupações com a dependência de poucos produtos agrícolas para impulsionar o dinamismo econômico brasileiro ${ }^{8}$. Há anos a agricultura vinha sendo avaliada como um caso de sucesso por várias razões, dentre as quais se destacam os ganhos de produtividade, os superávits comerciais e o crescimento de sua participação no PIB, cabendo à lavoura da soja grande responsabilidade por esse desempenho. Na década de 1990, essa lavoura se destacou, ocupando o primeiro lugar no ranking dos produtos agrícolas exportados. A produção nacional, de 15 bilhões de toneladas na safra de 1990/91, ultrapassou 50 bilhões de toneladas na safra de 2002/ 03, e a previsão foi de 61,4 bilhões de toneladas de soja para a safra de $2004 / 05^{9}$.

Esse crescimento da produção de soja resultou do efeito conjunto do aumento da área cultivada e da produtividade. A primeira safra da década registrou média de 1,6 t/ha, e, tomando esse número como referência, até a safra 1996/97 o índice de produtividade acumulou 46\%, com taxa média anual de crescimento de $6,5 \%$. Nas três safras seguintes, a produtividade teve pequeno aumento, elevando o índice para pouco acima de 150, mas na safra de 2000/01 superou 170. Daí em diante, o índice variou um pouco, mas sem evidenciar tendência, significando que nos últimos anos o crescimento da produção de soja resultou somente do brusco incremento da área cultivada (Tabela 1).

\footnotetext{
8 "A agricultura foi do céu ao inferno em apenas um ano" (Zafalon, 2005, p.b3). O repórter apontou três causas para essa reversão. A primeira delas foi a queda de até $35 \%$ dos preços dos principais produtos comercializados pelo Brasil no mercado externo; a segunda, a apreciação cambial, uma vez que os insumos para a safra de 2004/ 2005 foram comprados quando o dólar estava a $\mathrm{R} \$ 3,20 \mathrm{e}$, no momento da comercialização da safra, recuou para $\mathrm{R} \$ 2,60$; e a última, a quebra de safra, que atingiu algumas regiões produto ras, sendo o Rio Grande do Sul o mais afetado.

9 Dados disponíveis em: http://www.agricultura.gov.br/pls/portal/docs/PAGE/MAPA/ESTATISTICAS/ CULTURAS/2.1.A.XLS. Acesso em: 17 Fev. 04.
} 
Tabela 1 - Índices de evolução da soja. Brasil, 1990/91-2004/05

\begin{tabular}{lcccc}
\hline Safra & Área & Produção & Produtividade & Exportação \\
\hline $1990 / 91$ & 100 & 100 & 100 & 100 \\
$1991 / 92$ & 98 & 126 & 128 & 133 \\
$1992 / 93$ & 110 & 150 & 136 & 151 \\
$1993 / 94$ & 118 & 163 & 138 & 204 \\
$1994 / 95$ & 120 & 168 & 141 & 188 \\
$1995 / 96$ & 109 & 151 & 138 & 220 \\
$1996 / 97$ & 117 & 170 & 146 & 282 \\
$1997 / 98$ & 135 & 204 & 151 & 234 \\
$1998 / 99$ & 133 & 200 & 150 & 186 \\
$1999 / 00$ & 139 & 210 & 152 & 207 \\
$2000 / 01$ & 143 & 250 & 174 & 261 \\
$2001 / 02$ & 168 & 272 & 162 & 296 \\
$2002 / 03$ & 190 & 338 & 178 & 400 \\
$2003 / 04$ & 218 & 323 & 148 & $-\underline{\text { nd }}$ \\
$2004 / 05\left({ }^{1}\right)$ & 229 & 399 & 174 & -nd \\
\hline
\end{tabular}

$\left({ }^{1}\right)$ Estimativa.

Fonte: <http://www.agricultura.gov.br/ e http://faostat.fao.org/>. Acesso em: 23 Fev. 05.

Ressalta-se que o aumento acelerado da área cultivada é um fenômeno relativamente recente. Entre 1990/91 e 1996/97, a área colhida mantevese relativamente estável, com média de 10,7 milhões de hectares, e os extremos foram de 9,6 e 11,7 milhões de hectares nas safras de 1991/92 e 1994/95, respectivamente. Da safra de 1997/98 até a de 2000/2001, elevou-se para a casa dos 13 milhões de hectares, com taxa média de crescimento de 5,3\% a.a. Daí em diante, passou a crescer aceleradamente, à taxa média de 12,4\% a.a., resultando na previsão de colheita de 22,3 milhões de hectares na safra de 2004/2005. Considerando-se os extremos da série, a área cultivada com soja foi acrescida em $129 \%$, enquanto o crescimento da produtividade foi de $74 \%$.

O efeito conjunto do aumento da área cultivada e dos ganhos de produtividade resultou no fato de que, da safra de 1990/91 até a de 1997/ 98, a produção dobrou, superou o triplo em 2002/03 e, para 2004/05, está previsto que a produção brasileira de soja será quadruplicada. Essa 
evolução foi puxada pelas exportações, cujo valor praticamente foi multiplicado por 4 entre 1991 e 2003 e elevou a participação nacional no mercado externo (market-share) de cerca de $15,7 \%$ do valor das exportações mundiais para $26,4 \%{ }^{10}$ (Tabelas 1 e 2 ).

O indicador de vantagem relativa na exportação (vre) de soja em grão, farelo e óleo no período de 1991-2003 apontou que o Brasil sustentou elevada competitividade em todos eles (Tabela 2). O resultado é sempre positivo e bem maior que zero, o que significa participação do produto no valor da exportação brasileira muito mais elevada que nos demais países. A evolução dessas estimativas ao longo do tempo dá a perspectiva do aumento da competitividade, e os resultados indicaram que o Brasil avançou no comércio internacional de soja em grão e óleo de soja, porém perdeu um pouco da competitividade com relação ao farelo.

Tabela 2 - Indicadores da composição e competitividade da exportação de soja. Brasil, 1991-2003

\begin{tabular}{|c|c|c|c|c|c|c|c|c|c|}
\hline \multicolumn{5}{|c|}{ Composição do Valor da Exportação (\%) } & \multirow{2}{*}{$\begin{array}{c}\text { Market- } \\
\text { share (\%) }\end{array}$} & \multicolumn{4}{|c|}{ Vantagem Relativa na Exportação } \\
\hline Ano & Grão & Farelo & Óleo & Total & & Grão & Farelo & Óleo & Total \\
\hline 1991 & 22,1 & 67,4 & 10,5 & 100,0 & 15,7 & 2,2 & 3,7 & 2,8 & 3,1 \\
\hline 1992 & 30,0 & 59,2 & 10,8 & 100,0 & 19,0 & 2,7 & 3,7 & 2,9 & 3,3 \\
\hline 1993 & 30,7 & 59,1 & 10,2 & 100,0 & 21,3 & 2,8 & 3,8 & 2,9 & 3,3 \\
\hline 1994 & 31,8 & 47,9 & 20,3 & 100,0 & 25,6 & 3,1 & 4,0 & 3,6 & 3,6 \\
\hline 1995 & 20,1 & 52,3 & 27,5 & 100,0 & 22,1 & 2,6 & 4,1 & 3,7 & 3,5 \\
\hline 1996 & 22,8 & 61,2 & 16,0 & 100,0 & 21,6 & 2,6 & 4,1 & 3,6 & 3,5 \\
\hline 1997 & 42,8 & 46,8 & 10,4 & 100,0 & 23,5 & 3,4 & 3,8 & 2,9 & 3,6 \\
\hline 1998 & 45,8 & 36,8 & 17,4 & 100,0 & 22,6 & 3,6 & 3,6 & 3,0 & 3,5 \\
\hline 1999 & 42,1 & 39,7 & 18,2 & 100,0 & 21,6 & 3,5 & 3,7 & 3,2 & 3,6 \\
\hline 2000 & 52,1 & 39,4 & 8,5 & 100,0 & 22,5 & 3,6 & 3,6 & 2,9 & 3,6 \\
\hline 2001 & 51,5 & 39,0 & 9,6 & 100,0 & 24,7 & 3,7 & 3,6 & 3,1 & 3,6 \\
\hline 2002 & 50,5 & 36,6 & 12,9 & 100,0 & 26,2 & 3,8 & 3,7 & 3,3 & 3,7 \\
\hline 2003 & 52,8 & 32,0 & 15,2 & 100,0 & 26,4 & 3,7 & 3,6 & 3,4 & 3,7 \\
\hline
\end{tabular}

Fonte: Dados básicos: FAOSTAT (2005).

\footnotetext{
${ }^{10}$ Pelos dados disponíveis em <http://aliceweb.mdic.gov.br>, em 2004 o valor das exportações de soja e derivados ultrapassou US\$ 10 bilhões, implicando crescimento de 400\% em relação a 1991. O balanço de oferta e demanda, elaborado pela Companhia Nacional de Abastecimento (CONAB), mostra que, na safra de 2003/04, foram destinados à exportação 40,6\% da produção nacional de grão, 45,1\% do óleo e $62,9 \%$ do farelo de soja (http:/ /www.agricultura.gov.br/pls/portal/docs/PAGE/MAPA/ESTATISTICAS/ CULTURAS).
} 
O farelo era o subproduto da soja em que o país se mostrava mais competitivo, com vre próximo de 4 no início da década de 1990 , enquanto para grão e óleo esse indicador era menor que 3 . De 1997 em diante, o vre do farelo apresentou pequena redução, enquanto os outros dois registraram aumento. Com isso, a diferença inicial foi neutralizada, e nos últimos anos da série os três subprodutos da soja ficaram praticamente empatados, com ligeira vantagem do produto in natura, que, de vre igual a 2,2 em 1991, evoluiu para mais de 3 a partir de 1997 e atingiu o pico de 3,8 em 2002 (Tabela 2).

A maior competitividade da soja em grão no comércio exterior se refletiu na composição das exportações. Entre 1991 e 2003, a participação desse grão aumentou de 22,1 para 52,8\% o valor das exportações de soja e derivados, enquanto a participação do farelo, de $67,4 \%$ em 1991, atingiu 32\% em 2003. A reversão das tendências ocorreu em 1997, ano em que o grão conquistou 20,0 pontos percentuais de participação no valor das exportações, enquanto o farelo de soja perdeu $14,4^{11}$ (Tabela 2).

A participação do óleo de soja no valor das exportações revelou razoável instabilidade, que pode estar relacionada à evolução dos preços dos seus substitutos. O produto começou a década de 1990 com participação em torno de $10 \%$, aumentou para mais de $20 \%$ em 1994 e 1995, seguiramse anos de altos e baixos, com ponto mínimo em 2000, quando contribuiu com $8,5 \%$. Nos três anos seguintes, sua participação foi crescente, fechando com $15,2 \%$ do valor exportado (Tabela 2 ).

Essa instabilidade do óleo de soja antes do início do século XXI pode ser reflexo da evolução dos preços mensais que, até 2001, apresentaram comportamento distinto do preço do grão e do farelo e, em várias ocasiões, caminharam em direção oposta. Os preços do grão e do farelo seguiram

\footnotetext{
${ }^{1}$ Há quem atribua essa mudança ao Decreto-Lei 87/96, de 13/09/1996, denominado Lei Kandir, que desonerou as exportações de produtos básicos e semi-elaborados de ICMS, estimulando a exportação de soja em grão em detrimento dos subprodutos farelo e óleo, que têm maior valor adicionado. Ver, por exemplo, Ponciano e Campos (2003) e Pereira (2004).
} 
sempre trajetória semelhante, com diferenças pouco expressivas. A partir de 2001, as três séries passaram a apresentar tendência semelhante (Figura 1).

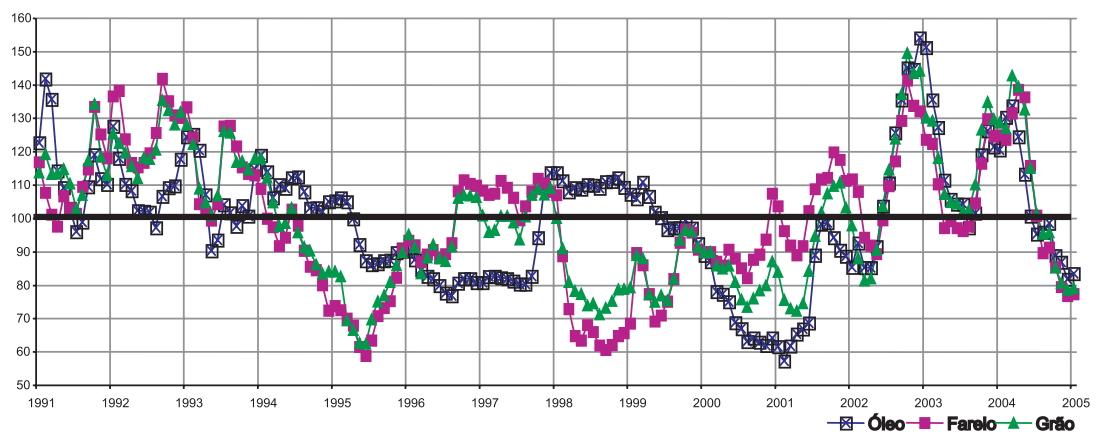

Fonte de dados básicos: DERAL, disponível em: http://www.IPEADATA.gov.br>.

Figura 1 - Evolução do preço real de soja, PR, jan./91-jan./05 (média jan./91-jan./05 = 100 - deflacionado pelo IGP-d)

Até meados de 1994, o preço real da soja em grão, deflacionado pelo IGP-DI, esteve acima da média do período de jan./91 a jan./05. Seguiramse dois anos de baixa, e no final de 1996 o preço voltou a superar a média e permaneceu em torno dela, com diferença inferior a 10 pontos percentuais, até fevereiro de 1998. Em seguida, caiu para nível bem abaixo da média e se manteve assim por 42 meses seguidos até que, antes do plantio da safra de 2001/2002, voltou a superá-la.

Na safra de 2002/03 houve forte recuperação do preço internacional do grão, o que levou os preços recebidos pelo produtor a ultrapassarem o pico de mais de uma década, em termos reais. O preço permaneceu anormalmente elevado até meados de 2004, quando despencou para nível inferior à média histórica dos últimos $14 \operatorname{anos}^{12}$.

\footnotetext{
12 Agravante é que essa queda de preço coincide com uma etapa de apreciação do real, que vem contribuindo para reduzir a receita dos exportadores. Carvalho (2005) mostrou que desde julho de 2004 a taxa de câmbio real efetiva, deflacionada pelo IPA, equiparou-se à observada após o Plano Real, ocasião em que o Brasil passou a enfrentar déficits comerciais.
} 
Essa evolução instável dos preços do grão não parece suficiente para motivar os ganhos de competitividade do produto brasileiro no mercado internacional. No entanto, há que se ressaltar que a lavoura experimentou avanço tecnológico razoável, sendo de se prever tendência de queda de preços sem comprometimento da lucratividade. Análises de Homem de Melo (2003) e Helfand e Rezende (2001) atribuíram o aumento da produtividade da terra ao maior acesso aos fertilizantes e defensivos em conseqüência da redução real de seus preços após a abertura comercial. Acrescente-se que a valorização da moeda nacional, de meados de 1994 a janeiro de 1999, também teve papel relevante para a baixa do preço dos insumos.

O confronto do preço da soja em grão com os preços dos insumos permitiu observar alternância de fases favoráveis e desfavoráveis ao produtor rural. Por favorável entende-se a ocasião em que o preço do produto cresceu mais que o dos insumos_e as relações de troca ultrapassaram 100\%. A série jan./91 a dez./03 registrou três etapas, em que predominaram variações positivas para o produtor: do final de 1992 ao início de 1994, nos anos de 1996 e 1997 e a partir de meados de 2001 (Figura 2).

Com exceção dos primeiros anos da década de 1990, o preço da soja em grão foi o fator predominante na determinação das relações de troca. É esse o caso do ponto mais crítico para o produtor rural, que aconteceu em 1995, quando a relação de troca entre preço do produto e dos dois tipos de_insumos ficou em torno de $75 \%$ não pelo aumento do preço destes últimos, que estavam relativamente estáveis durante esse ano, mas por queda repentina no preço da soja em grão. De 1995 até o início do ano de 1999, o preço real dos insumos esteve predominantemente abaixo da média, colocando em evidência que os altos e baixos das relações de troca decorreram de mudanças drásticas nos preços da soja em grão. Nessa etapa, a valorização da moeda nacional tornava os insumos importados mais baratos enquanto inibia a receita das exportações em reais. A alta das relações de troca observadas em 1996 e 1997, bem como a baixa dos anos seguintes, decorreu basicamente de mudanças na cotação internacional da soja em grão (Figuras 1, 2 e 3). 
Maria Auxiliadora de Carvalho, César Roberto Leite da Silva \& Arthur Antonio Ghilardi

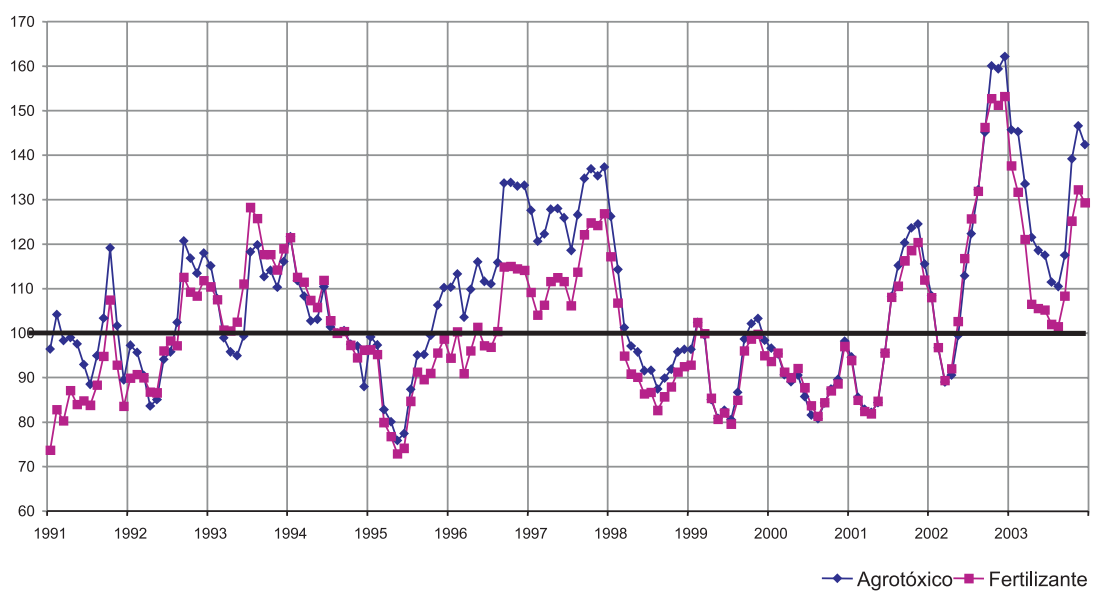

Fontes de dados básicos: DERAL e CONAB, disponíveis em http:// www.agricultura.gov.br

Figura 2 - Relações de troca entre soja em grão e insumos, no período de 1991-2003 (agosto/94 = 100).

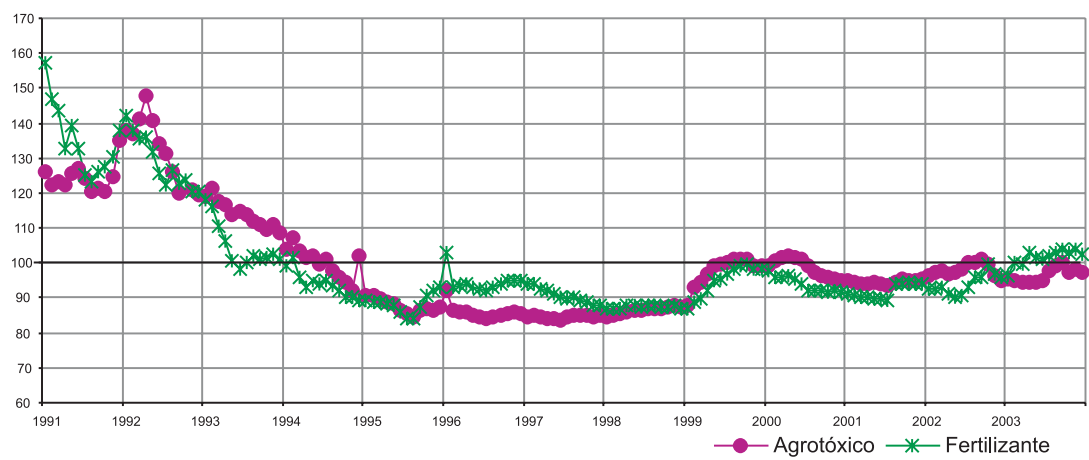

Fontes de dados básicos: CONAB, disponíveis em http://www.agricultura.gov.br

Figura 3 - Evolução do preço real de agrotóxicos e fertilizantes, no período de jan./1991-dez./2003 (média jan./1991- dez/2003 deflacionado pelo IGP-DI). 
No período seguinte à desvalorização da moeda de janeiro de 1999, os preços dos fertilizantes e agrotóxicos subiram para próximo da média histórica da série, com certo viés de baixa. Já o preço da soja passou por acentuadas flutuações, de forma que as relações de troca atingiram o índice mínimo igual a 75 em meados de 1999 e o máximo de 150 no final de 2002.

Os ganhos de competitividade da soja e sua importância crescente para a economia brasileira ficam mais evidentes quando se observa a participação do saldo comercial de soja no PIB agrícola $\left(y_{k i}\right)$ : representava menos de 7\% em alguns anos da década de 1990 e elevou a participação para 12,4\% em 2001 e para 16,6\% em 2003. Além disso, em 1991 a participação da soja no total das exportações brasileiras $\left(x_{k i}\right)$ era de $6,4 \%$ e ultrapassou 10\% em 1997, 2002 e 2003. Com isso, sua contribuição para o intercâmbio comercial agrícola $\left(q_{k i}\right)$, que não alcançava $1 / 5$, passou para em torno de $1 / 4$ entre 1992 e 2000 e se elevou para cerca de $1 / 3$ nos dois últimos anos da série (Tabela 3 ). 
Maria Auxiliadora de Carvalho, César Roberto Leite da Silva \& Arthur Antonio Ghilardi

Tabela 3 - Indicadores de competitividade da soja. Brasil, 1991-2004

\begin{tabular}{ccccc}
\hline Ano & $y_{k i}\left({ }^{1}\right)$ & $x_{k i}\left({ }^{2}\right)$ & $q_{k i}\left({ }^{3}\right)$ & $c_{k i}\left({ }^{4}\right)$ \\
\hline 1991 & 6,4 & 6,4 & 19,9 & 34,9 \\
1992 & 9,0 & 7,5 & 24,8 & 32,8 \\
1993 & 9,5 & 8,0 & 24,3 & 32,4 \\
1994 & 7,7 & 9,5 & 26,4 & 33,7 \\
1995 & 6,0 & 8,2 & 21,3 & 40,4 \\
1996 & 6,9 & 9,3 & 23,4 & 54,7 \\
& 8,9 & & & \\
1997 & & 10,8 & 27,9 & 44,0 \\
1998 & 7,3 & 9,3 & 24,3 & 47,1 \\
1999 & 8,5 & 7,9 & 22,0 & 54,5 \\
2000 & 8,8 & 7,6 & 25,8 & 47,7 \\
2001 & 12,4 & 9,1 & 28,5 & 57,7 \\
2002 & 15,0 & 10,0 & 31,5 & 60,0 \\
2003 & 16,6 & 11,1 & 34,4 & 63,4 \\
\hline
\end{tabular}

(1) Participação do saldo comercial de soja no PIB agrícola.

(2) Participação da soja no total das exportações do país.

${ }^{3}$ ) Participação do comércio de soja no comércio total dos produtos agrícolas do país.

$\left({ }^{4}\right)$ Participação dos insumos (fertilizantes, corretivos e defensivos) no custo de produção de soja.

Fontes de dados básicos: FAOSTAT, IPEADATA, SINDAG, ANDA, IEA e Agrianual.

O avanço tecnológico que elevou a produtividade da lavoura da soja em mais de $70 \%$ em cerca de 10 anos naturalmente contribuiu para os ganhos de competitividade. Entretanto, em conjunto com a elevação dos preços após 1999, implicou crescimento dos gastos com fertilizantes, corretivos e defensivos_no custo de produção $\left(c_{k i}\right)$ que, da casa dos $30 \%$ no começo da década de 1990 , atingiram cerca de $60 \%$ no começo do novo milênio.

A lavoura da soja é a que mais consome insumos no país. No início da década de 1990 sua participação no consumo de defensivos não atingia $30 \%$, já a partir de meados dessa década ultrapassou $1 / 3$, chegando a $44,2 \%$ em 2003. Enquanto isso, sua participação nos gastos com fertilizantes e corretivos evoluiu de 16,5\% em 1991 para cerca de $23 \%$ 
entre 1993 e 1996. De 1997 a 2000, alcançou a média de 29\% e, depois disso, passou para mais de 30\%, fechando a série com participação de $37,7 \%$ (Tabela 4).

A partir da participação da soja no consumo de defensivos, fertilizantes e corretivos, foram estimados os gastos com importação desses insumos destinados à lavoura. Dessa estimativa, pôde-se observar que os US\$ 12 milhões gastos com defensivos importados em 1991 foram multiplicados por 17, atingindo US\$ 215 milhões em 2003. Considerandose esses extremos da série, o dispêndio de divisas com fertilizantes e corretivos foi multiplicado por 9, passando de US \$ 75 milhões para US\$ 664 milhões._Com isso, o gasto com importação de fertilizantes, corretivos e defensivos no valor das exportações de soja $\left(i_{k i}\right)$, que representava menos de 5\% no início da década de 1990, superou 8\% a partir de 1998 e atingiu dois dígitos em 2000 e 2003 . Assim, conclui-se que todos os indicadores apontam aumento da competitividade brasileira no comércio de soja, o que até pode ser interpretado como autêntica no dizer de Fajnzylber (1988), uma vez que também se observou aumento expressivo da produtividade. $\mathrm{O}$ avanço tecnológico da cultura foi obtido à custa de crescimento acelerado do emprego de defensivos, fertilizantes e corretivos, resultando no fato de que parcela expressiva das divisas obtidas com a exportação foi despendida com importação, comprometendo parte dos ganhos de competitividade. 
Tabela 4 - Tabela 4 - Exportação de soja e participação no consumo e importação de insumos. Brasil, 1991-2003

\begin{tabular}{|c|c|c|c|c|c|c|c|c|c|}
\hline \multirow{3}{*}{ Ano } & \multirow{2}{*}{\multicolumn{2}{|c|}{$\frac{\text { Participação da Soja }}{\text { Defensivo Fertilizante }}$}} & \multicolumn{4}{|c|}{ US\$ milhão } & \multirow{3}{*}{$\begin{array}{l}i_{k i} \\
\left({ }^{4}\right)\end{array}$} & \multirow{2}{*}{\multicolumn{2}{|c|}{$\frac{\text { Índice }}{\text { Exportação Importação }}$}} \\
\hline & & & \multirow{2}{*}{$\begin{array}{r}\text { Exportação } \\
\text { Soja } \\
\end{array}$} & \multicolumn{3}{|c|}{ Importação $\left({ }^{3}\right)$} & & & \\
\hline & $\left({ }^{1}\right)$ & $\left({ }^{2}\right)$ & & Defensivo & Fertilizante & Soma & & Soja & Insumo \\
\hline 1991 & 27,6 & 16,5 & 2.031 & 12 & 75 & 87 & 4,3 & 100 & 100 \\
\hline 1992 & 27,6 & 19,8 & 2.696 & 17 & 104 & 121 & 4,5 & 133 & 139 \\
\hline 1993 & 28,6 & 23,1 & 3.076 & 13 & 139 & 152 & 5,0 & 151 & 175 \\
\hline 1994 & 31,1 & 22,0 & 4.138 & 27 & 166 & 193 & 4,7 & 204 & 221 \\
\hline 1995 & 29,7 & 22,9 & 3.824 & 31 & 174 & 206 & 5,4 & 188 & 236 \\
\hline 1996 & 32,0 & 22,6 & 4.462 & 35 & 202 & 237 & 5,3 & 220 & 272 \\
\hline 1997 & 33,3 & 29,9 & 5.730 & 71 & 348 & 419 & 7,3 & 282 & 480 \\
\hline 1998 & 34,6 & 28,4 & 4.755 & 99 & 285 & 383 & 8,1 & 234 & 440 \\
\hline 1999 & 34,5 & 29,2 & 3.784 & 102 & 263 & 365 & 9,7 & 186 & 419 \\
\hline 2000 & 35,2 & 28,3 & 4.200 & 94 & 409 & 502 & 12,0 & 207 & 576 \\
\hline 2001 & 34,0 & 32,6 & 5.297 & 104 & 414 & 517 & 9,8 & 261 & 594 \\
\hline 2002 & 38,1 & 35,0 & 6.009 & 116 & 447 & 563 & 9,4 & 296 & 646 \\
\hline 2003 & 44,2 & 37,7 & 8.125 & 215 & 664 & 879 & 10,8 & 400 & 1.009 \\
\hline
\end{tabular}

$\left({ }^{1}\right)$ Percentual calculado a partir do valor das vendas.

(2) Percentual calculado a partir do volume das vendas de fertilizantes e corretivos.

$\left(^{3}\right)$ Calculado considerando-se que a participação da soja no valor importado é proporcional à sua participação também no consumo de insumos.

$\left({ }^{4}\right)$ Participação dos insumos importados na exportação de soja.

Fontes dos dados básicos: ANDA e SINDAG e FAOSTAT.

\section{Conclusões}

A soja despontou, em meados da década de 1990, como a grande estrela do comércio exterior brasileiro e foi a principal responsável por uma longa fase de otimismo quanto às perspectivas da agricultura, o que prevaleceu até 2004. A partir do conceito de competitividade relacionado ao desempenho das exportações, pôde-se atestar o sucesso desse produto, com a ressalva de que entre 1991 e 2003: 
a) Sua participação no valor das exportações brasileiras evoluiu de 6,4 para 11,1\%,_e o market-share do país, de 15,7 das exportações mundiais de soja, aumentou para 26,4.

b) A produção total mais que triplicou; inicialmente, o crescimento procedia mais do avanço tecnológico que de aumentos de área plantada; a partir de 2000/01, não houve mais incrementos de produtividade da terra e o crescimento da produção resultou exclusivamente do aumento de área.

c) O aumento da produtividade da lavoura implicou crescimento dos gastos com insumos (fertilizantes, corretivos e defensivos), e 1/3 do custo de produção evoluiu para mais de $60 \%$.

d) O aumento da produção foi impulsionado pelas exportações, que foi multiplicada por 4; enquanto isso as despesas com importação de insumos foram multiplicadas por 10.

e) A participação da exportação de soja se elevou de menos de 7 para quase $17 \%$ do PIB agrícola e de menos de $1 / 4$ para mais de $1 / 3$ no intercâmbio comercial agrícola brasileiro.

f) O Brasil revelou vantagem relativa na exportação de soja e seus derivados, mas a partir de 1997 houve aumento da competitividade do produto em grão e redução da de farelo.

Esse conjunto de indicadores, enquanto aponta os ganhos de competitividade brasileira no mercado de soja, expõe também uma de suas maiores fragilidades: a elevada dependência de poucos produtos primários como fonte de divisas. Essa característica resulta em alternância de fases de otimismo e pessimismo ao sabor da conjuntura dos produtos que lideram as exportações.

A expansão da soja, impulsionada pela conjuntura externa (aumento da demanda, preços elevados, quebras de safra, estoques reduzidos etc.), gerou um ambiente de otimismo que parecia duradouro. Bastou um ano 
de queda nos preços internacionais (2004) para se evidenciar que a competitividade alcançada no mercado internacional não é sustentável, bem como despertar certo pessimismo decorrente da elevada concentração das fontes de divisas.

\section{Referências}

BRANDÃO, A. S. P.; REZENDE, G. C.; MARQUES, R. W. C. Crescimento agrícola no período 1999-2004, explosão da área plantada com soja e meio ambiente no Brasil. Brasília: IPEA, Jan. 2005 (Texto para discussão, n. 1062).

CARVAlHO, M. A. Taxa de câmbio e saldo comercial brasileiro. Informações Econômicas, São Paulo, v. 35, 2, p. 64-69, Fev. 2005.

DIAS, G. L. S.; AMARAL, C. M. Mudanças estruturais na agricultura brasileira: 1980-1998. Santiago de Chile: CEPAL, 2001. (Serie desarrollo productivo, 99).

FAJZYLBER, F. Competitividad internacional: evolución y lecciones. Revista de la CEPAL, Santiago de Chile, n. 36, p. 7-24, Dec. 1988.

FAOSTAT database. Disponível em: <http://www.fao.org>. Acesso em: Fev. 2005.

FERREIRA, C. R. P. T. Fertilizantes entregues ao consumidor final no Brasil, 1987-95. Série Informações Estatísticas da Agricultura, São Paulo, v. 7, n. 2, p. 1-64, 1996.

GASQUES, J. G.; CONCEIÇÃO, J. C. P. R. Indicadores de competitividade e de comércio exterior da agropecuária brasileira. Brasília: IPEA, Set. 2002 (Texto para discussão, n. 908). 
GASQUES, J. G. et al. Condicionantes da produtividade da agropecuária brasileira. Revista de Política Agrícola, Brasília, v. 13, n. 3, p. 73-90, Jul.-Set. 2004.

HAGUENAUER, L. Competitividade: conceitos e medidas - Uma resenha da bibliografia recente com ênfase no caso brasileiro. Rio de Janeiro: UFRJ/IEI, 1989. (Texto para discussão, n. 211).

HELFAND, S. M.; REZENDE, G. C. Brazilian agriculture in the 1990s: impact of the policy reforms. Rio de Janeiro: IPEA, Abr. 2001 (Texto para discussão, n. 785).

HOMEM DE MELO, F. A abertura comercial e o papel dos aumentos de produtividade na agricultura brasileira. Estudos Instituto Futuro Brasil. Disponível em: <http://www.ifb.com.br/ documentos/hdemelo.pdf >. Acesso em: 6 Mar. 2003.

NEVES, E. M. et al. Fertilizantes no plano real: estratégias empresariais e demanda. Piracicaba, SP: ESALQ/USP, Jul. 2002a.

NEVES, E. M. et al. Defensivos agrícolas no Brasil: estratégias empresariais, evolução no consumo e demanda relativa. Piracicaba, SP: ESALQ/USP, Jul. 2002b.

PEREIRA, S. R. A evolução do complexo soja e a questão da transgenia. Revista de Política Agrícola, Brasília, v. 13, n. 2, p. 26-32, Abr./Jun. 2004.

PONCIANO, N. J.; CAMPOS, A. C. Eliminação dos impostos sobre as exportações do agronegócio e seus efeitos no comportamento da economia. Revista Brasileira de Economia, Rio de Janeiro, v. 57, n. 3, p. 637-658, Jul./Set. 2003.

VICENTE, J. R. Mudança tecnológica, eficiência e produtividade total de fatores na agricultura brasileira, 1970-95. Economia Aplicada, São Paulo, v. 8, n. 4, p. 729-760, Out./Dez. 2004. 
VOLLRATH, T. L. Competitiveness and protection in world agriculture. Agriculture Information Bulletin, USDA, n. 567, Jul. 1989.

\title{
ZAFALON, M. Socorro "fácil” ameaça agronegócio profissional. Folha de São Paulo, São Paulo, 3 Mar. 2005. Caderno B, p. 3.
}

\begin{abstract}
The high Brazilian external dependence turns the persecution for foreign reserves a permanent concern. This paper analyzes soybean competitiveness after 1990 as it led Brazilian agricultural exports and became its main exchange value source. By using several indicators it concludes for an increasing competitiveness of the grain and decreasing for cake of soybeans since 1997. During the ninety decade there were expressive increases of crop productivity, but after that the production was due to area increases; from 1991 to 2003 doubled the share of inputs (fertilizers, corrective and pesticides) in the production cost, the expense with those imported inputs was multiplied by ten, while soybean and its derived product export value was multiplied by four; the reached competitiveness is considered not maintainable since the export value concentration exposes the country to risks related to international conjuncture.
\end{abstract}

Key words: Competitiveness, agriculture, soybean, external market. 
REVISTA DE ECONOMIA E AGRONEGÓCIO, VOL.3, $N^{o} 3$ 